\title{
IMPORTÂNCIA DAS CONDIÇÕES TERMODINÂMICAS NOS EVENTOS EXTREMOS DE PRECIPITAÇÃO NA CIDADE DE BELÉM E REGIÃO METROPOLITANA
}

\author{
FELIPE DO SOUTO DE SÁ GILLE, MARIA AURORA SANTOS DA MOTA \\ ${ }^{1}$ Universidade Federal do Pará, Belém, PA, Brasil \\ felipesagille@hotmail.com, aurora@ufpa.br
}

Recebido Setembro 2013 - Aceito Abril 2014

\begin{abstract}
RESUMO
O objetivo desta pesquisa foi verificar a importância dos fatores termodinâmicos na ocorrência de eventos extremos de precipitação em Belém (PA) e região metropolitana, no período de agosto de 2008 a dezembro de 2009. O estudo da termodinâmica da atmosfera foi realizado a luz das teorias da Energia Potencial Disponível para a Convecção (CAPE) e, da Energia de Inibição da Convecção (CINE). Para classificar os eventos extremos de precipitação foi utilizado o método dos decis, a fim de associá-los aos valores da CAPE e da CINE. Observou-se que a região estudada possui forte atividade convectiva durante todo o ano, e que nem sempre CAPE alta e CINE baixa produz precipitação. Esta situação determina convecção profunda, mas para haver precipitação existe a necessidade da forçante dinâmica, inclusive para a ocorrência de eventos extremos de precipitação no período chuvoso a forçante dinâmica é a ITCZ, e no período seco o que contribui é a Linha de Instabilidade (LI). Então quando o processo de precipitação dependeu, exclusivamente, da CAPE, foi necessário um valor alto para gerar convecção profunda e por consequência precipitação, enquanto, que no processo de precipitação com contribuição dinâmica não foi necessário um valor tão significativo da CAPE.

Palavras-chave: CAPE, CINE, Precipitação, eventos extremos.
\end{abstract}

\begin{abstract}
IMPORTANCE OF THERMODYNAMIC CONDITIONS DURING EXTREME PRECIPITATION EVENTS OVER BELÉM CITY AND METROPOLITAN REGION

The purpose of this research was to verify the importance of thermodynamic factors on the occurrence of extreme precipitation events in the city of Belém (PA) and its metropolitan area, during the period of August 2008 to December 2009. The study of the atmosphere thermodynamics was based on the theories of Convective Available Potential Energy (CAPE) and Convective Inhibition Energy (CINE). To classify the extreme precipitation events the decis method was used in order to associate them to the CAPE and CINE values. It was verified that the studied region has strong convective activity during all the year, and that not always high CAPE and low CINE determine precipitation. Those situations in fact determine profound convection, but to ensure precipitation, dynamic enforcement is required. For the occurrence of extreme precipitation events during the rainy season the ITCZ is the forcing dynamic and during the dry season the squall lines contribute to them. Then when the precipitation process is exclusively CAPE dependent, a high CAPE value is required in order to generate deep convection and, consequently, precipitation. Otherwise, for dynamic contribution precipitating process a significant value of CAPE is not needed.
\end{abstract}

Keywords: CAPE, CINE, precipitation, extreme events. 


\section{INTRODUÇÃO}

A liberação de calor latente é uma das principais fontes para o desenvolvimento dos distúrbios que ocorrem na atmosfera tropical, pois o armazenamento da energia potencial é pequeno devido ao gradiente de temperatura também ser pequeno. A maior quantidade de calor latente liberado está associada com os sistemas convectivos. Outras fontes de energia, além do calor latente, que devem ser consideradas, são o fluxo de calor da superfície e a radiação infravermelha. Estes parâmetros foram estudados por Neelin e Held (1987) onde verificaram que a variação destes dois parâmetros controla a convergência atmosférica e, naturalmente a precipitação mediante seus efeitos conjuntos no suprimento de energia estática úmida da atmosfera.

A fim de conhecer melhor a atmosfera tropical e melhorar os modelos de previsão, Rennó e Williams (1992) relacionaram o aumento da Energia Potencial Disponível para a Convecção (CAPE) e da convecção profunda na atmosfera tropical, com a diminuição da Energia de Inibição da Convecção (CINE) e do processo de mistura, pois destroem a flutuabilidade positiva. O calor necessário para gerar esta flutuabilidade é retirado da camada superficial e uma parte dele é transportado para atmosfera livre, de onde é irradiado para o espaço (Rennó e Ingersoll,1996). O saldo desta energia é transformado em trabalho mecânico, o qual é utilizado na manutenção dos movimentos convectivos. A quantidade de trabalho produzida por este movimento convectivo dá uma medida da quantidade de equilíbrio estático da CAPE, a qual aumenta com a elevação da temperatura da superfície. Além da CAPE e da CINE, parâmetros como cisalhamento de vento e umidade relativa do ambiente, também são importantes para o desenvolvimento da convecção profunda (James e Markoski,2010).

O período chuvoso na Amazônia Tropical é iniciado pela influência de Sistemas Sinóticos condicionado pelo aumento da quantidade de umidade na Camada Limite Planetária (CLP) e da diminuição da temperatura no topo, reduzindo a CINE (Greco et al., 1990). Porém, mais de $80 \%$ desta precipitação é oriunda de convecção profunda. Assim, a compreensão do que controla as mudanças desta convecção profunda torna-se necessária para determinar a sazonalidade da precipitação. $\mathrm{O}$ início do período chuvoso será determinado não somente pela fonte de energia do meio ambiente, a qual é indicada pela CAPE (Neelin e Held, 1987), mas também por condições dinâmicas, como o movimento de ascensão da parcela e cisalhamento do vento, que liberam a energia do ambiente para o desenvolvimento da convecção profunda (Garstang et al., 1994; Cohen et al., 1995).

O crescimento dos sistemas convectivos organizados, em escala sazonal, como as ondas de leste (Kayano, 1979; Cohen et al., 1995) ou oscilações intra-sazonais (Knutson e Weickmann, 1987, Jones e Weare, 1993) depende da energia liberada destes sistemas para a atmosfera e de como a extração de energia é feita. As mudanças da temperatura da superfície, algumas vezes, não afetam diretamente o início da convecção, mas são responsáveis pelas mudanças na circulação e assim, afetam o desenvolvimento da convecção. Logo as condições termodinâmicas modulam a frequência e a intensidade da flutuabilidade da parcela (Fu et al., 1998).

Os sistemas de meso e grande escala intensificam a atividade convectiva local através do cisalhamento do vento, gerando CAPE, que favorecem a formação de tempestades, pois as condições termodinâmicas locais estão relacionadas com a profundidade e longevidade da convecção (Le Mone et al., 1998).

Betts et al. (2009) relacionaram as trovoadas fortes com o período de transição da estação seca para a estação chuvosa e com o início da estação chuvosa, quando a CAPE é maior em quase todos os locais da Amazônia. Portanto, concluíram que com uma CAPE elevada a probabilidade de ocorrer uma tempestade seria muito grande. Entretanto, nem sempre valores grandes da CAPE estão relacionados com precipitações fortes (Mota e Nobre, 2006). Ressalta-se que é importante avaliar os valores da CINE que poderão indicar as condições de enfraquecimento da instabilidade, não permitindo assim o desenvolvimento da convecção profunda e consequentemente a formação da tempestade.

A cidade de Belém (PA) representa a maior aglomeração urbana na Amazônia, nesta região foram registradas as maiores taxas de ocupação (Castro, 2003). Essa também é uma das regiões mais chuvosas com quase $3000 \mathrm{~mm}$. $\mathrm{Ano}^{-1}$.

Com o objetivo de estudar os parâmetros que contribuem para a formação de tempestades Tavares e Mota (2012) realizaram um estudo dos diversos índices termodinâmicos. Verificaram que a CAPE e a CINE são adequados para a Cidade de Belém, para a estação chuvosa, mas é necessário fazer uma adequação para o período seco levando-se em consideração a CINE. A formação de tempestades pode estar associada a diversos fenômenos meteorológicos, tais como a Zona de Convergência Intertropical (ZCIT) que é um dos fenômenos meteorológicos que mais influencia as condições de tempo em toda Amazônia (Cavalcanti et al., 2009) e, por conseguinte, na Cidade de Belém. Além de outros que influenciam de forma significativa as condições de tempo em toda a região.

Portanto, o objetivo geral deste trabalho é verificar a importância dos fatores termodinâmicos e dinâmicos para a ocorrência de eventos extremos de precipitação, na Cidade de Belém (PA) e região metropolitana, no período de agosto de 2008 a dezembro de 2009.

\section{MATERIAIS E MÉTODOS}

Para o desenvolvimento desta pesquisa foram utilizados dados observacionais de precipitação e de radiossondagem no 
período de $1^{\circ}$ de agosto de 2008 a 31 de dezembro de 2009 .

A precipitação diária foi coletada em dez pontos distribuídos pela cidade de Belém e em mais seis pontos em cidades da região metropolitana, a saber: nas estações meteorológicas do Destacamento de Controle do Espaço Aéreo de Belém (DTCEA-BE), Instituto Nacional de Meteorologia (INMET) e da Universidade Federal do Pará (UFPA), nos pontos pluviométricos de Jurunas, Maguari, Mangueirão, Marambaia, Montese (2 pontos de observação) e Umarizal na cidade de Belém, e de Ananindeua, Carananduba, Icoaraci, Marituba, Outeiro e Santa Bárbara, na área metropolitana, exceto Belém.

A localização dos pontos de coleta de dados é apresentada nas Figuras 1 e 2.

Os dados de radiossondagens são da Estação Meteorológica de Altitude (EMA) localizada no Aeroporto Internacional de Belém (PA), no período de 01 de agosto de 2008 a 31 de Dezembro de 2009, nos horários de 0000 e 1200 UTC, disponíveis no endereço http://www.weather.uwyo.edu/ upperair/sounding.html.
Também, foram utilizados, para o período considerado, análises de imagens de satélite e de cartas sinóticas para verificar as condições de tempo na região estudada, as quais foram obtidas através dos endereços htpp://www.redemet.aer.mil.br e htpp:// www.sat.dundee.ac.uk_e de informações cedidas pelo Centro Nacional de Meteorologia Aeronáutica (CNMA).

Foram selecionados nesta pesquisa os dados de precipitação extrema, dos dados da precipitação acumulada em 24 horas, no período de 01/08/2008 a 21/12/2009.

De posse dos dados de precipitação, de todos os pontos coletados, foi verificada a precipitação total máxima e feita a média espacial dos pontos de coleta em cada dia. Para encontrar e selecionar os eventos extremos de precipitação foi adotado o método dos decis (Xavier et al., 2007). Este método diz que: se um conjunto de dados é esquematizado em ordem de grandeza, o valor médio que divide a série em duas partes iguais é chamado de mediana. Fisicamente, o primeiro e o nono decis apresentam os casos mais raros da série, aqueles que, embora sejam em número muito reduzido, correspondem a $10 \%$ do total de toda a série, sendo que os valores inferiores ao primeiro decil são os

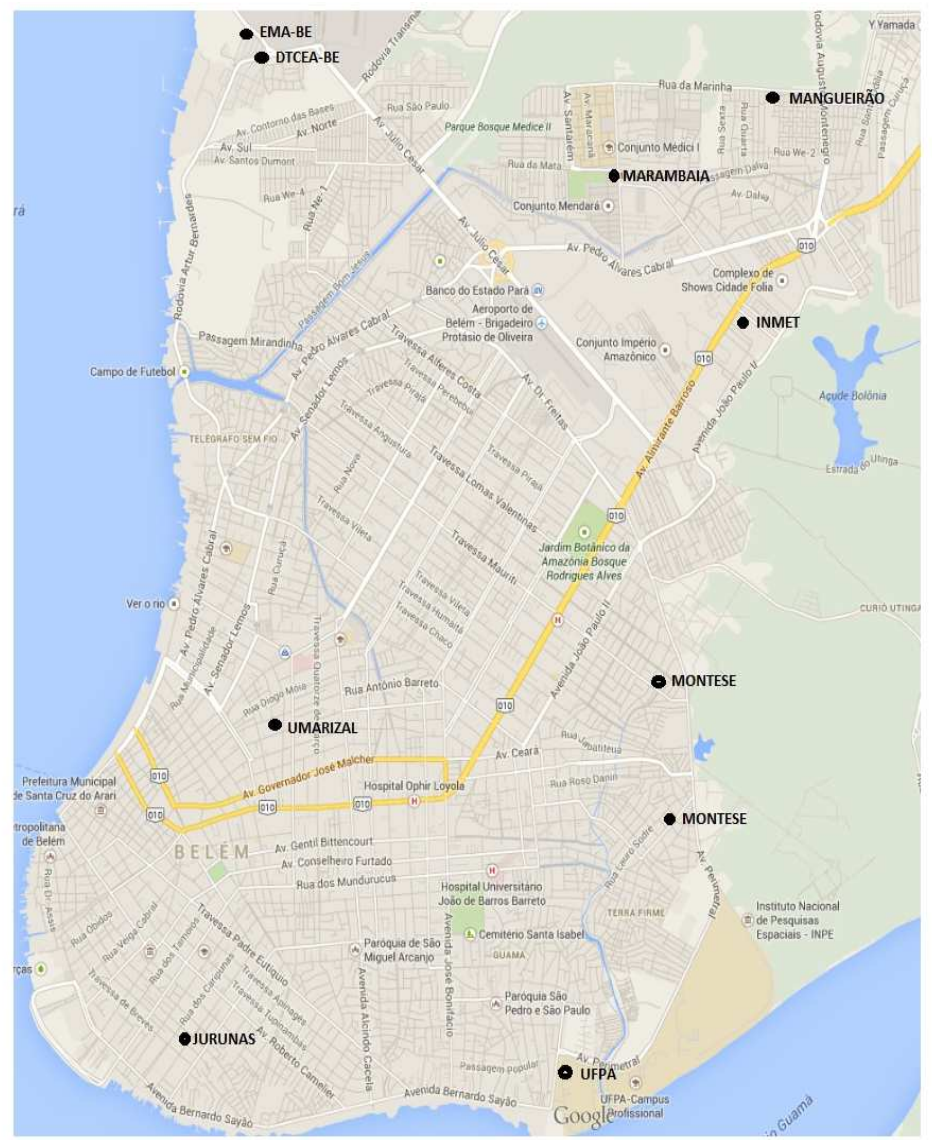

Figura 1 - Localização da Estação Meteorológica de Altitude de Belém (EMA-BE) e dos pontos de coleta de precipitação nos bairros da Cidade de Belém (PA).

Fonte: Site www.google.com.br. 


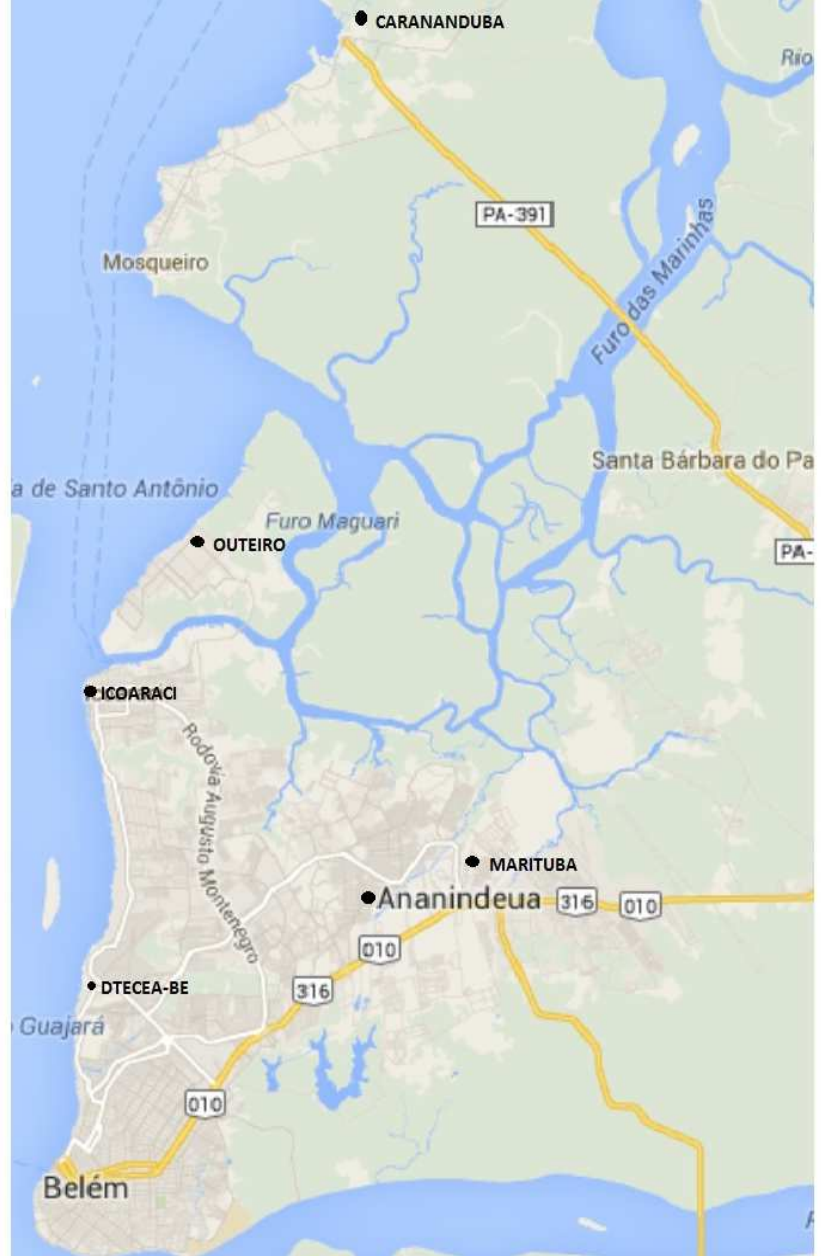

Figura 2 - Localização da Estação Meteorológica de Altitude de Belém (EMA-BE) e dos pontos de coleta de precipitação na região metropolitana da Cidade de Belém (PA).

Fonte: Site www.google.com.br.

$10 \%$ menores, assim como, os valores superiores ao nono decil são $10 \%$ maiores. O presente estudo escolheu o nono decil para a precipitação total diária ser considerada chuva diária extrema.

Verificou-se, então, que os valores de precipitação entre $47,9 \mathrm{~mm} /$ dia representa o nono decil e chuvas diárias iguais ou superiores a este valor foram consideradas precipitações diárias extremas. Logo, para o período analisado, foram encontrados 42 eventos extremos de precipitação, sendo o mais intenso de todos $96,3 \mathrm{~mm} /$ dia. Após a seleção dos eventos e dos dias que ocorreram, foram analisadas as condições termodinâmicas e sinóticas a fim de verificar quais foram suas contribuições para a ocorrência da precipitação extrema.

Foi analisado, também, o campo de vento, vorticidade, divergência e a umidade da atmosfera em níveis médios com o objetivo de verificar as contribuições de cada parâmetro no desenvolvimento da convecção profunda, pois as principais forçantes que modulam as correntes verticais dentro de células convectivas são: a força devido ao gradiente vertical de pressão e a flutuabilidade. (Nascimento, 2005).

A análise das condições termodinâmicas foi feita avaliando a variação da CAPE e da CINE. Os dados de radiossondagem foram utilizados para os cálculos de CAPE e CINE utilizando as equações sugeridas por Emanuel et al. (1994) e Rennó e Willians, (1992), respectivamente. Verificou-se, também, a umidade em níveis médios, da sondagem, através da análise do diagrama termodinâmico SKEW T LOG P e depois foram elaborados gráficos a fim de verificar a variação da CAPE e CINE e a possível relação com a precipitação máxima e média acumulada para a Cidade de Belém e região metropolitana.

O cálculo da CAPE foi feito segundo a equação, sugerida por Emanuel et al. (1994):

$$
C A P E=\int_{N C E}^{N E}\left(\alpha_{p}-\alpha_{a}\right) d P
$$

onde: $\alpha_{p}$ é o volume específico da parcela e $\alpha_{a}$ o volume específico do ambiente.

A CINE é a área negativa do diagrama termodinâmico. Ela existe quando a diferença entre a Temperatura Virtual da Parcela $\left(\mathrm{Tv}_{(\mathrm{par})}\right)$ e a Temperatura Virtual do Ambiente $\left(\mathrm{Tv}_{(\mathrm{amb})}\right)$ for negativa. Isto significa que a pseudo-adiabática do deslocamento da parcela de ar está mais fria que o ambiente. Os valores-limite de CAPE, para a região tropical, estão representados na Tabela 1 .

\section{RESULTADOS E DISCUSSÃO}

A análise da variação da precipitação, da CAPE e da CINE no período compreendido entre $1^{\circ}$ de agosto de 2008 e 31 de dezembro de 2009 é feita neste capítulo. Esta análise procurou determinar quais são as influências das condições termodinâmicas na ocorrência dos eventos extremos de precipitação na Cidade de Belém e região metropolitana.

Os resultados comprovam que, nem sempre, valores altos da CAPE estiveram relacionados com ocorrência de precipitação, conforme ilustra a Figura 3. Nestes casos a ausência de precipitação ocorreu devido a falta de um mecanismo dinâmico, forte o suficiente, para elevar a parcela de ar da superfície até o NCE fazendo com que a convecção fosse disparada.

Foi observado, que para gerar chuva, devido exclusivamente, aos fatores termodinâmicos, é necessário que o valor da CAPE seja superior a $2.000 \mathrm{~J} / \mathrm{kg}$. Os resultados são semelhantes às conclusões obtidas por Mota e Nobre (2006), quando fizeram a análise da CAPE para o Estado de Rondônia, e encontraram que a CAPE deveria estar acima de $4000 \mathrm{~J} / \mathrm{kg}$ para que a convecção profunda e precipitação pudessem ocorrer na ausência da forçante dinâmica. 


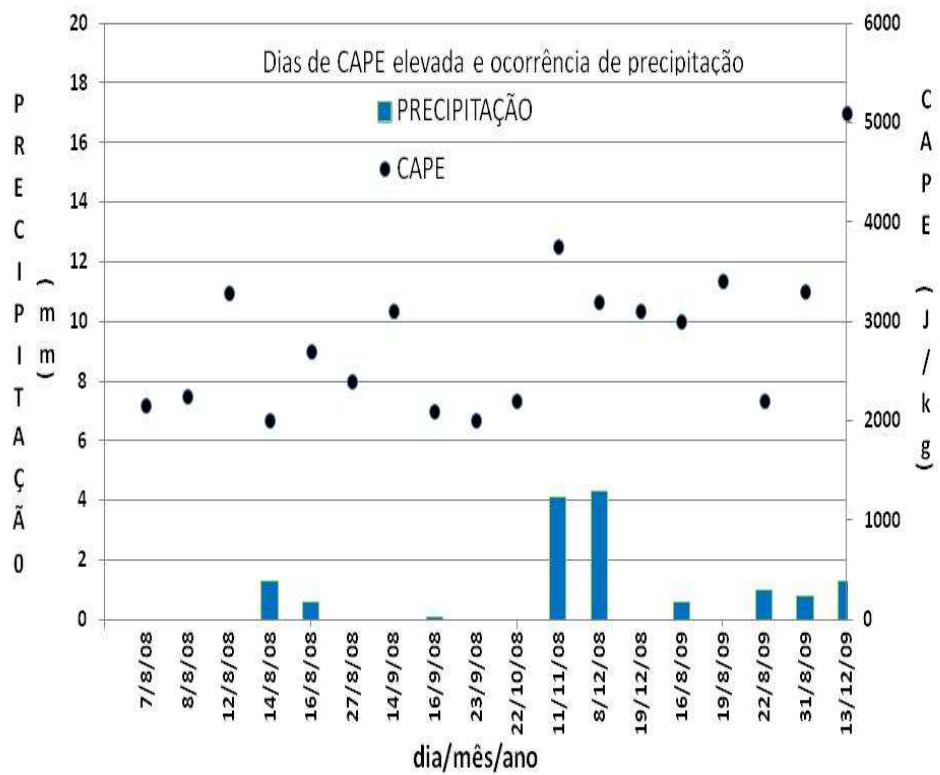

Figura 3 - Dias de CAPE elevada e ocorrência de precipitação.

No período estudado, aconteceram valores extremos de precipitação com baixos valores da CAPE, neste caso, os extremos de precipitação ocorreram devido ao efeito dinâmico de brisa, que formou linhas de instabilidade junto a costa de Belém gerando forte precipitação na região, como discutido por Gamache e Houze (1983), Garstang et al. (1994), Cohen et al. (1995); Alcantara et al. (2011).

A presença da Zona de Convergência Intertropical (ZCIT) na região de estudo e de frentes frias na região sudeste do Brasil também influenciaram na variabilidade da precipitação em Belém, pois contribuíram para o aumento da convergência em baixos níveis, e para o aumento da umidade na atmosfera. Estes resultados são semelhantes aos encontrados por Xavier et al. (2007) para a bacia hidrográfica do Ceará e por Tavares e Mota (2012), para a Cidade de Belém e região metropolitana. A ZCIT, forçante dinâmica de grande escala, intensifica a convecção e gera tempestades severas,

Tabela 1- Valores da CAPE.

\begin{tabular}{|c|c|}
\hline CAPE $(\mathbf{J} / \mathbf{k g})$ & CONDIÇÕES DE INSTABILIDADE \\
\hline$>0$ até 1000 & Limite para formação da convecção profunda \\
\hline 1000 até 2500 & Convecção profunda moderada \\
\hline 2500 até 4000 & Convecção profunda forte \\
\hline$>4000$ & Convecção Severa \\
\hline
\end{tabular}

o que ocasiona grandes prejuízos materiais para sociedade. Foi, também, constatado neste estudo, que valores baixos da CINE não determinam ocorrência de precipitação, e que se os efeitos termodinâmicos se associarem aos efeitos dinâmicos a quantidade de precipitação, ocorrida na região estudada, será maior do que aquela associada a estes fatores agindo individualmente.

\subsection{Variabilidade da Precipitação}

A Figura 4 apresenta a variação da precipitação acumulada total mensal (média espacial dos pontos de coleta) no período analisado, para a Cidade de Belém e região metropolitana. Observa-se que ocorreu maior quantidade de precipitação entre os meses de janeiro e junho de 2009, sendo que o máximo ocorreu em março (354 mm). Este período com maior quantidade de precipitação total mensal (média espacial dos pontos de coleta) foi chamado, nesta pesquisa, de "período chuvoso". A influência da ZCIT, na região, acontece devido a variação da radiação recebida por cada hemisfério, tanto que a partir de setembro, a ZCIT vai se deslocando do hemisfério norte para o hemisfério sul (Tarakanov, 1982).

O período de menor precipitação total mensal (média espacial dos pontos de coleta), chamado de período seco neste trabalho, ocorreu entre os meses de julho e dezembro dos anos de 2008 e 2009. Sendo que a menor precipitação total mensal (média espacial dos pontos de coleta) de ocorreu em novembro de 2009 (49 mm).

Observam-se na Figura 5, quarenta e dois (42) eventos extremos de precipitação ( $>47,9 \mathrm{~mm}$ para a mostra analisada), 


\section{Variação da Precipitação Média Mensal}

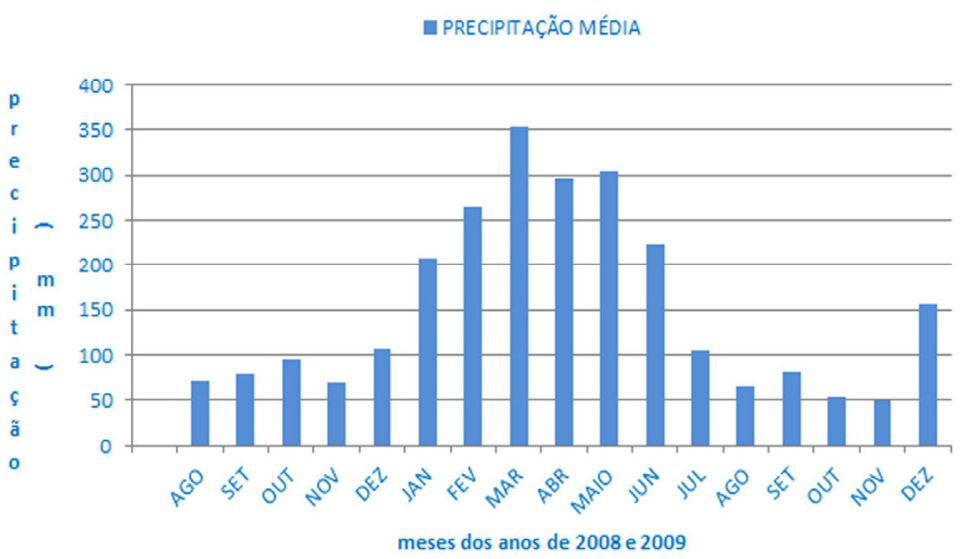

Figura 4 - Variação da Precipitação Média Mensal.

os quais ocorreram tanto no período chuvoso, quanto no período seco.

O período chuvoso teve maior frequência de eventos extremos, vinte e oito eventos e também a maior precipitação acumulada em 24 horas (96,3 mm), observada no dia 01/04/2009, no Bairro de Montese. Considerando que, a precipitação total mensal (média espacial dos pontos de coleta) da do mês de abril de 2009 foi de $297 \mathrm{~mm}$, neste único dia choveu um terço da precipitação total mensal (média espacial dos pontos de coleta) deste mês.

Após selecionar os dez maiores eventos extremos de precipitação, de toda a série, se verifica que oito ocorreram no período chuvoso, enquanto que, no período seco só ocorreram dois. O mesmo resultado encontrou Tavares (2009) quando associou a maior ocorrência de eventos extremos ao período chuvoso. Além disso, foi observado que no mês de abril, apesar de não ser o mês de maior precipitação, aconteceram cinco dos dez eventos extremos de chuva, os quais tiveram a influência da ZCIT, em sua marcha climatológica para o hemisfério norte. Foi encontrado nas análises de satélite grande quantidade de Altostratus (AS), associados a nebulosidade cumuliforme da ZCI. Estes AS foram responsáveis pela maior parte da precipitação contínua que ocorreu na região Tropical.

\subsection{Variabilidade da CAPE, CINE e Precipitação}

A variabilidade média mensal da CAPE, CINE e da Precipitação total mensal (média espacial mensal dos pontos de coleta) é apresentada na Figura 6. Pode ser observado que o comportamento da CAPE no período seco (julho a dezembro) foi semelhante ao período chuvoso (janeiro a junho), pois em ambos os períodos ocorreram valores inferiores a média de todo período estudado (linha preta contínua $-1.350 \mathrm{~J} / \mathrm{kg}$ ). Os valores da CAPE média mensal, do período seco, nem sempre foram maiores que os valores da CAPE média mensal do período chuvoso, como pode ser verificado nos meses de novembro/2008 (1.200 J/kg), julho/2009 (1.130 J/kg), setembro/2009 (1.100 J/ $\mathrm{kg})$, outubro/2009 (1.100 J/kg) e novembro/2009 (1.250 J/kg), todos do período seco, com os meses de abril $/ 2009(1.330 \mathrm{~J} / \mathrm{kg})$, maio/2009 (1.500 J/kg) e junho/2009 (1.410 J/kg) do período chuvoso. Os resultados encontrados, neste trabalho, diferem de Tavares e Mota (2012), pois a análise aqui apresentada se refere a média mensal da CAPE e não aos valores absolutos diários da CAPE os quais foram relacionados, pelo autor, quando comparou a ocorrência de um evento extremo no período seco com o do período chuvoso.

Então, a variação mensal da CAPE foi significativa, independente dos períodos seco e chuvoso, com valores entre $900 \mathrm{~J} / \mathrm{kg}$ (mínimo) e $1900 \mathrm{~J} / \mathrm{kg}$ (máximo). Caracterizando a forte atividade convectiva durante todo o ano, na região tropical, principalmente na Amazônia, pois mesmo com CAPE pequena, ainda assim, representa atividade convectiva. Logo, para que ocorra a convecção profunda e gerar precipitação, basta a atuação da forçante dinâmica para disparar o processo.

Em relação aos valores médios mensais a CINE, no período chuvoso, apresentou valores menores que $300 \mathrm{~J} / \mathrm{kg}$, em todos os meses, enquanto que, no período seco, seus valores foram superiores a $300 \mathrm{~J} / \mathrm{kg}$ também em todos os meses. Fica claro, então, que a CINE é maior no período seco. Desta forma, a parcela de ar tem uma barreira maior a ser quebrada, o que dificulta o desenvolvimento das nuvens e, consequentemente, a ocorrência de precipitação. Outra característica importante se refere aos valores médios mensais da CINE no período seco. Quando seus valores foram superiores a $400 \mathrm{~J} / \mathrm{kg}$ a precipitação total mensal (média espacial dos pontos de coleta) deste período, não foi maior que $100 \mathrm{~mm}$, como foi observado no ano de 


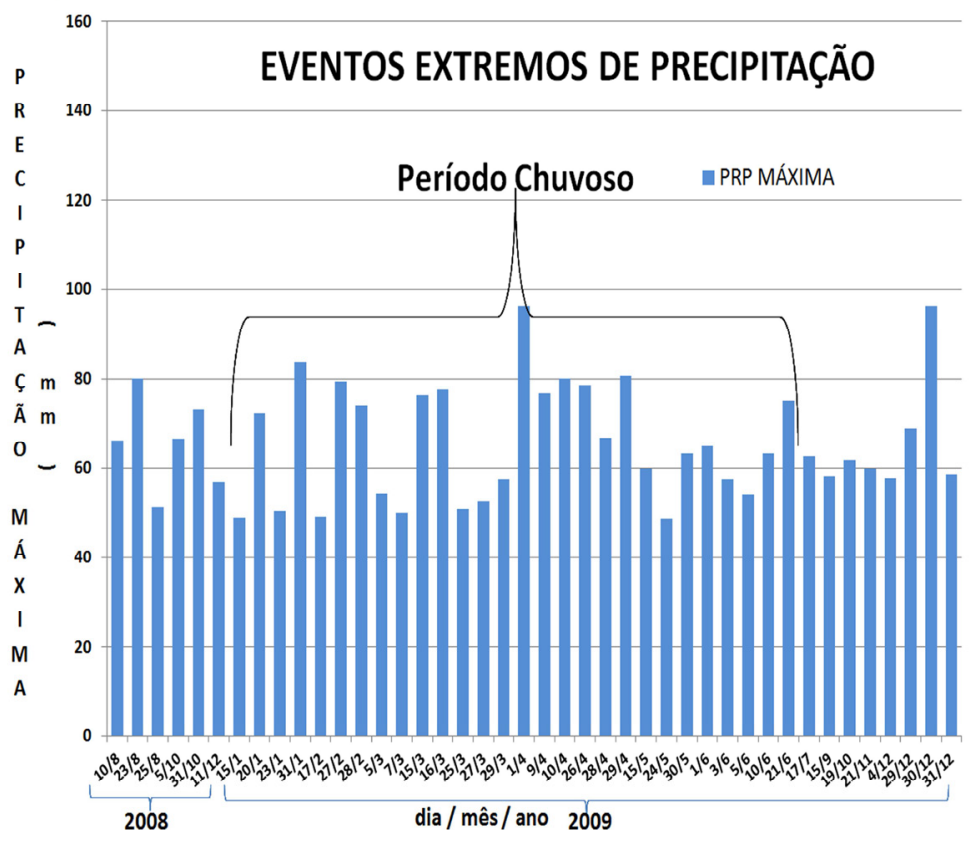

Figura 5 - Eventos Extremos de Precipitação.

2008 e 2009. Logo, fica evidente, que a CINE é fundamental para o desenvolvimento das nuvens e, por conseguinte para a ocorrência da precipitação, mas quando ela possui um valor grande, impede a subida da parcela de ar inibindo a convecção e a precipitação. Ou seja, a CINE representa uma barreira significativa para liberação da instabilidade condicional na região tropical (Williams e Rennó, 1993).

A Figura 7 apresenta os quarenta e dois (42) eventos extremos de precipitação, CAPE e CINE. É possível verificar que os valores da CAPE, associados aos eventos extremos, no período seco, são maiores que a CAPE no período chuvoso. Valores da CAPE maiores que $1500 \mathrm{~J} / \mathrm{kg}$ estiveram presentes quando ocorreu a maioria dos eventos extremos no período seco, e menor do que $1500 \mathrm{~J} / \mathrm{kg}$ na maioria dos eventos do período chuvoso. Verifica-se, ainda, que valores da CAPE inferiores a $700 \mathrm{~J} / \mathrm{kg}$ só estiveram presentes em sete eventos, um ocorreu no período seco e seis no chuvoso. Dos dez maiores eventos extremos a CAPE só esteve inferior a $1000 \mathrm{~J} / \mathrm{kg}$ em um ocorrido em 09/04/2009, o que caracteriza a necessidade de haver uma CAPE de pelo menos $1000 \mathrm{~J} / \mathrm{kg}$, na região tropical, para sustentação da convecção profunda, mantendo as circulações convectivas contra as perdas dissipativas mecânicas (Rennó e Ingersoll, 1996).

A CINE esteve superior a $250 \mathrm{~J} / \mathrm{kg}$ em quinze eventos sendo seis ocorridos no período chuvoso e sete no seco. Pode-se verificar, então, que a CINE apresentou valores significativos nos dias que ocorreram os eventos extremos. Confirmando que apesar dos valores da CINE serem menores que a CAPE, são expressivos para a convecção, pois a CINE significa uma barreira a ser superada para a liberação da instabilidade condicional nos trópicos (Rennó e Willians, 1992).

Desta forma, ficou claro que as condições termodinâmicas são essenciais para a liberação da convecção, formação de nuvens e ocorrência de precipitação na região tropical.

Apesar da CAPE ser menor no período chuvoso, este período também é marcado por CINE menor, o que favorece a convecção. A CINE menor aliada a forçante dinâmica de grande escala, ou seja, o posicionamento mais ao sul da ZCIT, favorece a maior ocorrência dos eventos extremos de precipitação.

No período seco, para que ocorra um evento extremo, existe a necessidade da CAPE estar mais alta, de preferência maior que $1.500 \mathrm{~J} / \mathrm{kg}$, sendo que em alguns eventos este valor chega a ser maior que $4.000 \mathrm{~J} / \mathrm{kg}$, como observado no dia 17/07/2009. Dos quatorze eventos extremos analisados, no período seco, onze ocorreram quando a CAPE estava com valor superior a $1.500 \mathrm{~J} / \mathrm{kg}$. Tal afirmação corrobora com Tavares (2009), que também encontrou, para o período seco, para a região de Belém, a maior ocorrência de eventos extremos de precipitação quando a CAPE estava superior a $1.000 \mathrm{~J} / \mathrm{kg}$.

A CINE, também, mais alta, neste período, não é um fator que impeça a precipitação. Valores maiores que $250 \mathrm{~J} / \mathrm{kg}$, apesar de inibir a subida do ar, são importantes e necessários para a formação de tempestades, as quais podem gerar eventos extremos de precipitação. Isto ocorre, pois em ambientes altamente instáveis a atividade convectiva é favorecida. Desta forma, ou seja, com a inibição presente, a instabilidade vai crescendo ao longo do dia devido ao 
aquecimento superficial. Assim alguns pontos mais isolados, onde os inibidores enfraquecem primeiro, serão os pontos preferenciais para o disparo da tempestade, logo elas poderão utilizar uma maior energia disponível, contribuindo com isso para o crescimento da nebulosidade cumuliforme. Este maior desenvolvimento vertical da nebulosidade, neste período, poderá acarretar junto com o cisalhamento vertical do vento, nuvens mais eletrizadas.

Outro ponto, a ser considerado, é a ocorrência de uma camada de ar seco em níveis médios. Este ar seco ajuda a promover a instabilidade convectiva devido à produção, por evaporação, de correntes descendentes capazes de gerar novos desenvolvimentos da nebulosidade e com isso sustentar a tempestade. $\mathrm{O}$ feito dinâmico também é fundamental para a ocorrência dos eventos extremos. Apesar de a ZCIT estar deslocada, nesta época do ano, para o hemisfério norte, as linhas de instabilidade, impulsionadas pela brisa aparecem com maior frequência. Estas linhas trazem umidade do oceano para o continente e ainda contribuem para aumentar a instabilidade da atmosfera, favorecendo, com isso, o desenvolvimento da atividade convectiva e assim aumentando a possibilidade da ocorrência de um evento extremo.

\section{CONCLUSÃO}

Ficou patente que, na estação chuvosa, os eventos extremos de precipitação estão associados a presença da ZCIT, forçante de grande escala, e a sua marcha climatológica entre os hemisférios norte e sul. Nesta estação, além da precipitação em forma de pancadas, de curta duração, grande parte da precipitação ocorre de forma contínua, ou seja, com duração superior a uma hora. Esta precipitação está intimamente ligada a nebulosidade estratiforme da ZCIT e ocorre preferencialmente durante a madrugada. $\mathrm{O}$ somatório das precipitações em forma de pancada, nuvens cumuliformes, com a precipitação contínua, oriunda da nebulosidade estratiforme, ocasionam os eventos extremos de precipitação deste período.

No período seco, a maioria, dos eventos extremos está associada ao efeito da brisa, que formam LI, as quais invadem a costa trazendo mais umidade para o continente e aceleram a subida vertical da parcela de ar. As frentes frias em seu deslocamento, também influenciam as condições de tempo em Belém, acarretando uma maior convergência em baixos níveis e também um maior cisalhamento do vento.

Os valores da CAPE, que estão relacionados com a ocorrência de um evento extremo de precipitação no período chuvoso, foram menores que no período seco, ou seja, a CAPE medida antes da ocorrência de um evento extremo de precipitação no período chuvoso é menor que a do período seco. Os altos valores da CAPE estão relacionados a ocorrência significativa de precipitação. Nestas ocasiões a ausência/ pequena precipitação ocorreu devido a pouca quantidade de vapor de água disponível na atmosfera, e/ou pela falta de um mecanismo forçante para elevar a parcela de ar.

Ficou evidente que a CINE é fundamental para o desenvolvimento das nuvens, mas não pode ser extremamente grande, se o for, a nebulosidade não terá o desenvolvimento vertical necessário para proporcionar uma precipitação significativa. Com a inibição presente, a instabilidade vai crescendo ao longo do dia devido ao aquecimento superficial.

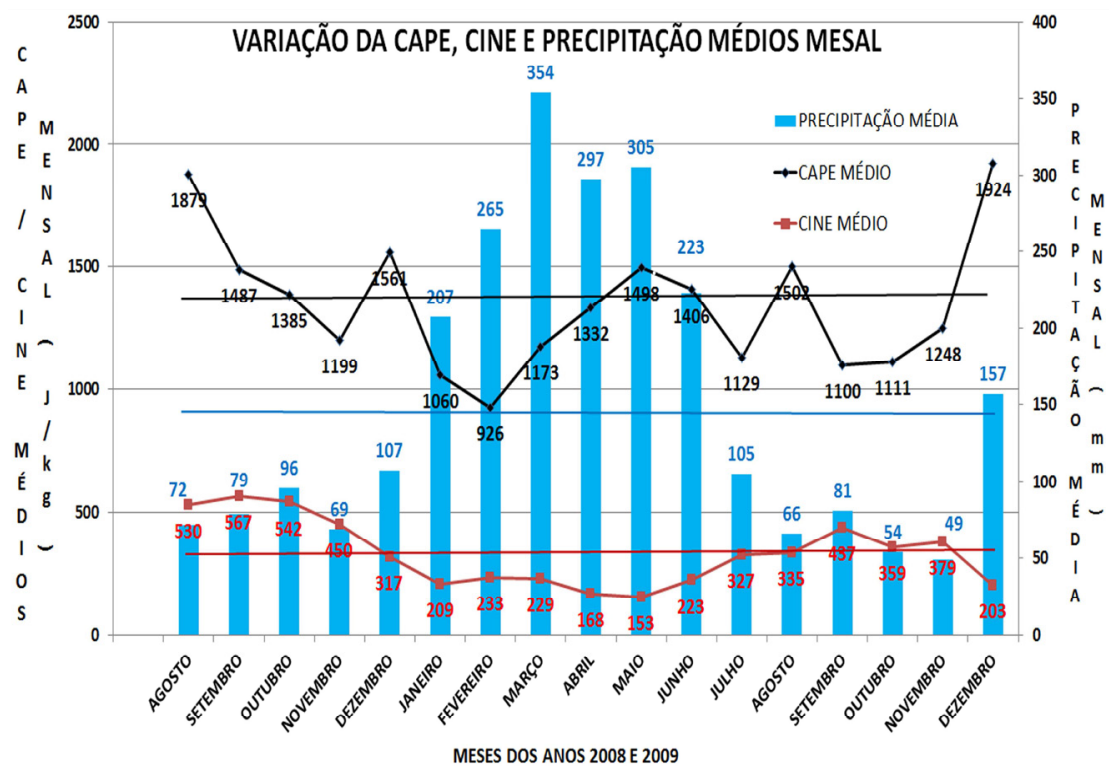

Figura 6 - Variação da CAPE, CINE e Precipitação Médios Mensal. 


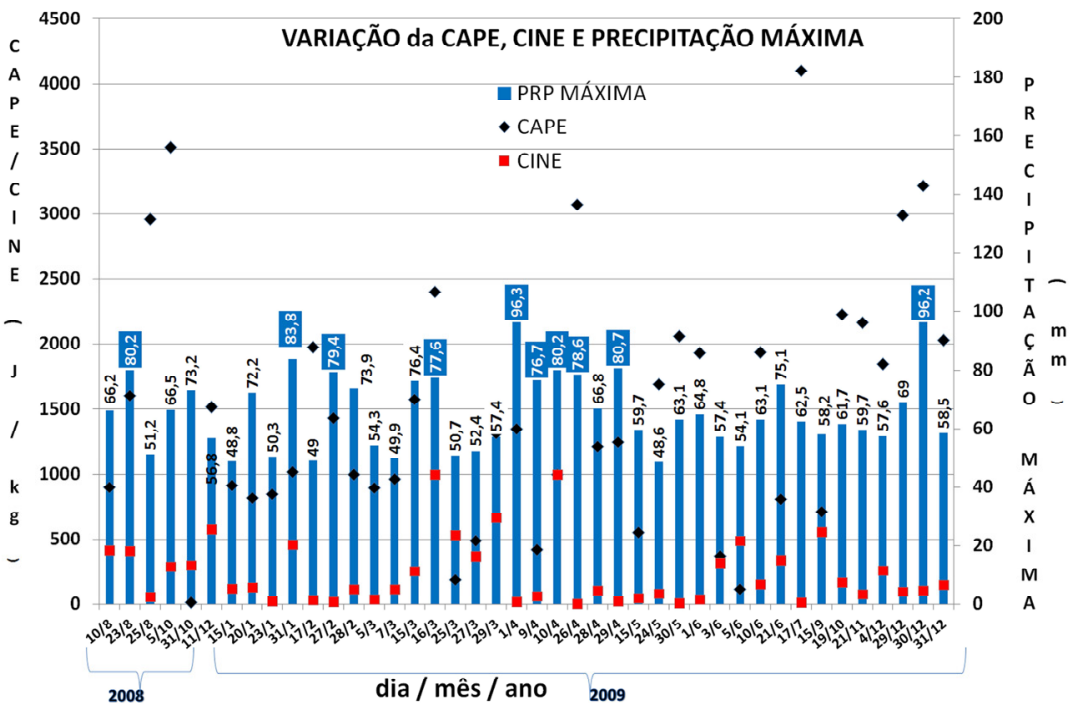

Figura 7 - Variação da CAPE, CINE e Precipitação Máxima.

Assim alguns pontos mais isolados, onde os inibidores enfraquecem primeiro, serão os pontos preferenciais para o disparo da tempestade, logo elas poderão utilizar uma maior energia disponível, contribuindo com isso para o crescimento da nebulosidade cumuliforme.

\section{5- AGRADECIMENTOS}

Os autores agradecem à Financiadora de Estudos e Projetos (FINEP) pelo financiamento do Projeto REMAM 1 e 2.

\section{REFERÊNCIAS BIBLIOGRÁFICAS}

ALCANTARA, C. R.; SILVA DIAS, M.A.F.; SOUZA, E. P.; COHEN, J.C.P. Verification of the role of the low level jets in Amazon squall lines, Atmospheric Research, v.100, p. 36-44, 2011.

BETTS, A. K.; SILVA DIAS, M.A.F., Progress in Understanding Land - Surface-Atmosphere coupling from LBA Research, Journal of Advances in Modeling Earth Sistems, v. 2, 20pp, 2009.

CASTRO, E. Geopolítica da Água e Novos Dilemas a Propósito da Amazônia e seus Recursos Naturais. In: Luis E. Aragon; Miguel Clüsener-Godt (Orgs.) Problemática do Uso Local e Global da Água da Amazônia. Belém: NAEA, 2003.p. 334.

CAVALCANTI, I. F. A.; FERREIRA, N. J.; SILVA DIAS, M. A .F.; JUSTI, M. G. A. Tempo e Clima no Brasil, Oficina de Textos, 2009.

COHEN, J. C. P.; SILVA DIAS, M. A. F.; NOBRE. C. A. Environmental conditions associated with Amazonian squall lines: A case study. Monthly Weather Review., 123, p. 3163-3174, 1995.
EMANUEL, K. A.; NEELIN, J. D.; BRETHERTON, C. S. On large-scale circulations in convecting atmospheres. Quarterly Journal of the Royal Meteorological Society, v. 120, n. 519, p. 1111-1143, 1994.

FU, R.; ZHU, B.; DICINSON, R. E. How Do Atmosphere and Land Surface Influence Seasonal Changes of Convection in the Tropical Amazon, Journal of Climate, v.12, p. 13061321, 1998.

GRECO, S. et al. Rainfall and surface kinematic conditions over central Amazonia during ABLE 2B. Journal Geophysical. Research., 95, 17 001-17 014, 1990.

GARSTANG, M.; MASSIE, Jr , H. L.; HALVERSON ,J.; GRECO S.; SCALA, J. Amazon coastal squall lines. Part I: Structure and kinematics, Monthly Weather Review, 122, p. 608-622, 1994.

GAMACHE, J.F.; HOUZE, R.A. Water budget of a meso-scale convective system in the tropics. Journal of Atmospheric Sciences, 40, p. 1835-1850, 1983.

JAMES, R. P.; MARKOWSKI, P. M. A numerical investigation of the effects of dry air aloft on quase-linear convective systems, Monthly Weather Review, v. 138, n. 1, p 140-161, 2010.

JONES, C.; WEARE, B. A time series analysis of evaporation and wind speed over the Amazon Basin. Preprints, Fourth Symp. on Global Change Studies, Anaheim, CA, Amerericam Meteorological Society., p. 423-426, 1993.

KAYANO, M. T. Um estudo climatológico e sinótico utilizando dados de radiossondagem de Manaus e Belém, INPE-1559TDL/013, São Jose de Campos, Brasil, p. 82, 1979.

KNUTSON, T. R.; WEICKMANN, K. M. 30-60 day atmospheric oscillations: Composite life cycles of convection and circulation anomalies. Monthly Weather Review, v. 115, p. 1407-1436, 1987. 
LE MONE, M. A.; ZIPSER, E. J.; TRIER, S. B. The Role of Environmental Shear and Thermodynamic Conditions in determining the structure and evolution of MCS during TOGA-COARE, Journal of Atmospheric Sciences, v.55, n. 12, p. 3493-3518, 1998.

MOTA, M. A. S; NOBRE, C. A. Relação da variabilidade da Energia Potencial Convectiva Disponível (CAPE) com a Precipitação e a Alta da Bolívia durante a campanha "WetAMC/LBA", Revista Brasileira de Meteorologia, Brasil, v.21, n.3b, p. 344-355, 2006

NASCIMENTO, E. L.Previsão de Tempestades Severas utilizando-se Parâmetros Convectivos e Modelos de Mesoescala: uma Estratégia Operacional Adotável no Brasil? Revista Brasileira de Meteorologia, v. 20, n.1, 2005.

NEELIN, J. D.; HELD, I. M. Modeling Tropical Convergence Based on the Moist Staticenergy Budget. Monthly Weather Review, v.115, p.3-12, 1987

RENNÓ, N.O; WILLIANS, E. An Analysis of the instability of the Tropical Atmosphere. American Meteorological Society, v. 2, p. 21-35, 1992.
RENNÓ, N. O.; INGERSOLL, A. P. Natural convection as a heat engine: a theory for CAPE, Journal of Atmospheric Sciences, v. 53, p. 572-585, 1996.

TARAKanov, G. G. Tropical Meteorology, Mir Published Moscou, 1982.

TAVARES, J. P. N. Tempestades Severas na Região Metropolitana de Belém: Avaliação das Condições Termodinâmicas e Impactos Sócio-econômicos, Dissertação de Mestrado, 2009

TAVARES, J. P. N.; MOTA, M. A. S. Condições termodinâmicas de eventos de precipitação extrema em Belém-Pa durante a estação chuvosa. Revista Brasileira de Meteorologia,v.27, n.2, 207 - 218, 2012.

WILLIAMS, E.; RENNÓ, N.O. An Analysis of the Conditional Instability of the Tropical Atmosphere. Monthly Weather Review, v. 121, v.1, p.21-36, 1993.

XAVIER, T. M.; XAVIER, A. F. S.; ALVES, J. M. B. Quantis e Eventos Extremos - Aplicações em Ciências da Terra e Ambientais. RDS Editora, Livrarias Livro Técnico, p. 278, 2007. 